\title{
Interaksi 3D Sensor Leap Motion untuk Menggenggam Benda Virtual
}

\author{
Lukman Hakim $^{1}$, Surya Sumpeno ${ }^{2}$, Supeno Mardi Susiki Nugroho ${ }^{3}$ \\ ${ }^{1,2,3}$ Fakultas Teknik Elektro dan Informatika, Kampus Institut Teknologi Sepuluh Nopember \\ Jl. Raya Keputih Sukolilo, Kota Surabaya, Jawa Timur 60111 \\ e-mail: lukman.manutd@gmail.com
}

\begin{abstract}
Abstrak - Penelitian ini membahas tentang interaksi 3D sensor Leap Motion untuk simulasi menggenggam Benda virtual Plastis. Sebuah interaksi 3D sensor Leap Motion yang digunakan sebagai simulasi untuk menggenggam benda virtual Plastis dengan menggunakan media objek telur virtual secara presisi dan akurasi yang tepat. Pada dasarnya menggenggam merupakan suatu kegiatan yang menerapkan kinerja motorik halus pada tangan untuk melakukan gerakan. Penggunaan sensor Leap Motion sebagai interaksi 3D dipakai untuk menggenggam objek maya dalam hal ini bentuk 3D telur virtual sebagai media praktiknya. Telur sendiri merupakan benda yang gampang distimulasi dan memiliki sifat texture yang halus untuk merespon segala bentuk gerakan pada genggaman tangan. Dalam penelitian Interaksi 3D Sensor Leap Motion untuk simulasi untuk menggenggam benda Virtual Plastis dengan menggunakan media objek telur virtual, ini di peruntukkan untuk mengetahui akurasi dan presisi dari pola gerakan tangan secara imersif. Pengembangan dari metode ini bertujuan untuk simulasi menggenggam benda atau objek maya dengan adanya interaksi pola gerakan tangan.
\end{abstract}

Kata kunci: leapmotion, $3 d$, virtual reality, benda, telur

Abstract - This study discusses about the 3D interaction of the Leap Motion sensor for the simulation of holding virtual plastic objects. A 3D interaction of the Leap Motion sensor that is used as a simulation to hold Plastis virtual objects by using virtual egg object media with precise and right accuracy. Basically, holding is an activity that applies fine motor performance on the hands to make movements. The use of the Leap Motion sensor as a $3 D$ interaction is used to hold virtual objects in this case a 3D form of virtual eggs as practice media. Eggs are objects that are easily stimulated and have subtle texture to respond to all forms of movement in the hands. In the 3D interaction Leap Motion Sensors for virtual plastic objects holding simulation by using virtual egg object media, it is intended to find out the accuracy and precision of immersive hand movement patterns. The development of this method aims to simulate holding virtual objects or objects with the interaction of hand movement patterns.

Keywords: leap motion, 3d, virtual reality, object, egg

\section{PENDAHULUAN}

Gerak tubuh manusia sangat di pengaruhi oleh kinerja otot yang ada pada setiap bagian tubuh. Jumlah otot yang tersebar diseluruh tubuh manusia memiliki fungsi-fungsi tersendiri serta respon yang berbeda dalam tubuh manusia. Tangan merupakan salah satu organ tubuh manusia yang vital. Kegiatan manusia banyak sekali yang di topang oleh tangan.

Otot pada tangan memliki peranan yang sangat penting untuk menjadi motor penggerak. Namun disamping itu juga rawan mengalami gangguan. Gejala penurunan kinerja otot manusia dapat di picu berbagai macam faktor, salah satunya faktor usia dan faktor kecelakaan. Faktor faktor tersebut dapat mengurangi kinerja otot pada manusia sehingga kinerjanya tidak optimal. Hal ini tentunya akan berdampak pada kualitas hidup manusia. Karena aktifitasnya akan terganggu dan tidak maksimal.

Dalam hal ini di butuhkan sebuah sistem simulasi untuk mengetahui tingkat presisi dan akurasi gerakan menggenggam pada suatu benda maya atau 3D di dunia virtual. Dengan mengetahui tingkat presisi dan akurasi ketika beriteraksi pada suatu benda virtual maka akan memudahkan sesorang untuk membuat sebuah ujicoba interaksi di benda-benda virtual lainnya.

Implementasi lainya pada penelitian ini digunakan sebagai alat gerakan menggenggam yang di aplikasikan nantinya disebuah industry yang mengharuskan adanya sebuah interaksi untuk menggengam pada suatu objek benda, misal robot untuk menggenggam benda atau menggambil benda dengan mengetahui tingkat presisi dan akurasi ketika memegang atau mengambil.

Proses mengenggam sendiri merupakan sebuah gerakan yang dilakukan tangan untuk menahan dan memegang suatu benda. dalam hal ini bentuk benda telur virtual diambil sebagai sampel karena bentuk ini (telur) pada dasarnya merupakan salah satu benda yang mudah didapatkan dan dekat degan manusia yang sifat dan karakternya sangat mudah menerima respon gerak tangan. Penggunaan telur virtual merupakan sebuah upaya praktis dan ekonomis dikarenakan meminimalisir tingkat kerusakan ketika menggenggam suatu benda real (telur asli) kerugian yang dialami apabila menggunakan benda tersebut lebih besar karena kesalahan dalam mengenggam akan membuat benda asli rusak. 


\section{STUdi PUSTAKA}

\subsection{Benda Virtual}

Secara umum benda Virtual atau tiga dimensi (3D) adalah bentuk dari sebuah benda yang memiliki panjang, lebar, dan tinggi dimana benda tersebut memiliki isi atau ruang. Dalam dunia komputer, pemodelan tiga dimensi adalah proses merancang atau menciptakan sebuah model yang mewakili objek tiga dimensi pada aslinya. Cris Broomhall (2011) menyatakan bahwa di dalam komputer, 3D (tiga dimensi) digambarkan sebagai sebuah gambar yang memiliki kedalaman. Secara umum tiga dimensi (3D) adalah bentuk dari sebuah benda yang memiliki panjang, lebar, dan tinggi dimana benda tersebut memiliki isi atau ruang. Dalam dunia komputer, pemodelan tiga dimensi adalah proses merancang atau menciptakan sebuah model yang mewakili objek tiga dimensi pada aslinya (Cris Broomhall, 2011). menyatakan bahwa di dalam computer 3D (tiga dimensi) digambarkan sebagai sebuah gambar yang memiliki kedalaman.

\subsection{Telur Virtual}

Telur virtual secara garis besar adalah gambaran berupa bentuk fisik yang memiliki sumbu $\mathrm{X}, \mathrm{Y}, \mathrm{Z}$. Telur virtual menunjukan sisi 3D telur dalam bentuk video maupun gambar yang mampu menjadi objek media pembelajaran dan penelitian telur dalam bentuk digital.

Selain itu bentuk telur yang oval membuat telur memiliki sifat yang mudah berubah jika diberi stimulus sentuhan atau tekanan seperti reaksi gerak menggelinding ataupun pecah jika diberi tekanan pada benda keras atau ketika jatuh. Sifat telur yang demikian menjadikan telur menjadi benda yang perlu diperhatiakan keamannya dalam penyimpanan ataupun membawanya.

Karakteristik 3D, mengacu pada tiga dimensi spasial, bahwa 3D menunjukkan suatu titik koordinat Cartesian $\mathrm{X}$, $\mathrm{Y}$ dan Z. Penggunaan istilah 3D ini dapat digunakan di berbagai bidang dan sering dikaitkan dengan hal-hal lain seperti spesifikasi kualitatif tambahan (misalnya: grafis tiga dimensi, 3D video, film 3D, kacamata 3D, suara 3D). Istilah ini biasanya digunakan untuk menunjukkan relevansi jangka waktu tiga dimensi suatu objek, dengan gerakan perspektif untuk menjelaskan sebuah "kedalaman" dari gambar, suara, atau pengalaman taktil.

\subsection{Menggenggam}

Menggenggam memiliki 3 arti. Menggenggam berasal dari kata dasar genggam. Menggenggam adalah sebuah homonim karena arti-artinya memiliki ejaan dan pelafalan yang sama tetapi maknanya berbeda. Arti dari menggenggam bisa masuk dalam jenis kiasan sehingga penggunaan menggenggam bisa bukan dalam arti kata yang sebenarnya. Menggenggam memiliki arti dalam kelas verba atau kata kerja sehingga menggenggam dapat menyatakan suatu tindakan, keberadaan, pengalaman, atau pengertian dinamis lainnya. Menggenggam berarti memegang dengan tangan terkepal.

\subsection{Leap Motion}

Leap motion merupakan sistem yang dapat mengenal gerakan tangan, jari tangan dan alat-alat yang mempunyai bentuk seperti jari [12]. Perangkat ini beroperasi pada jarak yang dekat dengan presisi yang tinggi dengan frame tingkat pelacakan, laporan posisi yang diskrit, gesture dan gerakan. Leap Motion menggunakan sensor optic dan cahaya inframerah. Sensor yang diarahkan sepanjang sumbu y saat controller dalam pengoperasian standart dan memiliki bidang panjang 150 derajat. Jarak efektif Leap Motion ialah memanjang diatas perangkat dari 25-600 milimeter (1 inci2 kaki).

\subsection{Colission Detection}

Dalam membuat game salah satu metode yang sering digunakan adalah Collision detection atau metode tabrakan antar benda. Metode Collision Detection mengacu pada cara mendeteksi suatu irisan dari dua obyek atau lebih. Pada metode ini bisa diaplikasikan pada permainan video game atau di bidang robotika. Ketika metode ini telah menentukan apakah obyek-obyek saling "bertabrakan" (collide), maka sistem pada collision detection akan juga menghitung waktu impact (time of impact), dan menjabarkan irisanirisan yang terjadi. Penyelesaian permasalahan untuk pendeteksian "tabrakan" tersebut memerlukan penggunaan secara ekstensif aljabar linier dan komputasi geometris.

Algoritma collision detection adalah proses pengecekan apakah beberapa buah objek spasial adanya saling bertumpuk atau tidak. Jika ternyata ada paling sedikit dua objek yang bertumpuk maka kedua objek tersebut dikatakan saling bertumpukan. Pada ruang spasial dua dimensi. Objek yang bertumpuk berarti spasialnya beririsan

\subsection{Naïve Bayes}

Naïve Bayes merupakan sebuah pengklasifikasian probalistik sederhana yang menghitung sekumpulan probabilitas dengan menjumlahkan frekuensi dan kombinasi nilai dari dataset yang diberikan. Algoritma menggunakan teorema bayes dan mengasumsikan semua atribut independen atau tidak saling ketergantungan yang diberikan oleh nilai pada variable kelas. Naïve Bayes juga didefinisikan semua atribut independen atau tidak saling ketergantungan yang diberikan oleh nilai pada variable kelas. Naïve Bayes juga didefinisikan sebagai pengklasifikasian dengan metode probabilitas dan static yang dikemukakan oleh ilmuan berdasarkan pengalaman di masa sebelumnya (saleh, 2015).

\section{MetodE}

Pada tahap selanjutnya adalah pembutan desain untuk uji coba interaksi untuk mengukur tingkat presisi dan akurasi pada saat menggenggam beda maya (telur virtual). Sehingga prosesnya sesuai dengan yang di tunjukkan gambar 3.1

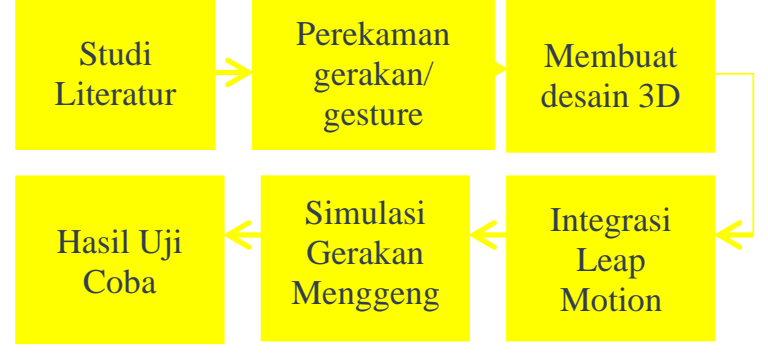


Gambar 3.1 Metode Sistem akurasi dan presisi interaksi pada benda virtual.

Dalam metode penelitian ini dibagi menjadi tiga tahapan utama yaitu: koleksi data dari Leap Motion, Ekstraksi fitur dan Proses Klasifikasi. Dari ketiga tahapan utama di atas maka ditunjukan pada Gambar 3.1. Upaya ini dilakukan untuk simulasi interaksi menggengam benda virtual untuk mencari tingakat akurasi dan presisi.

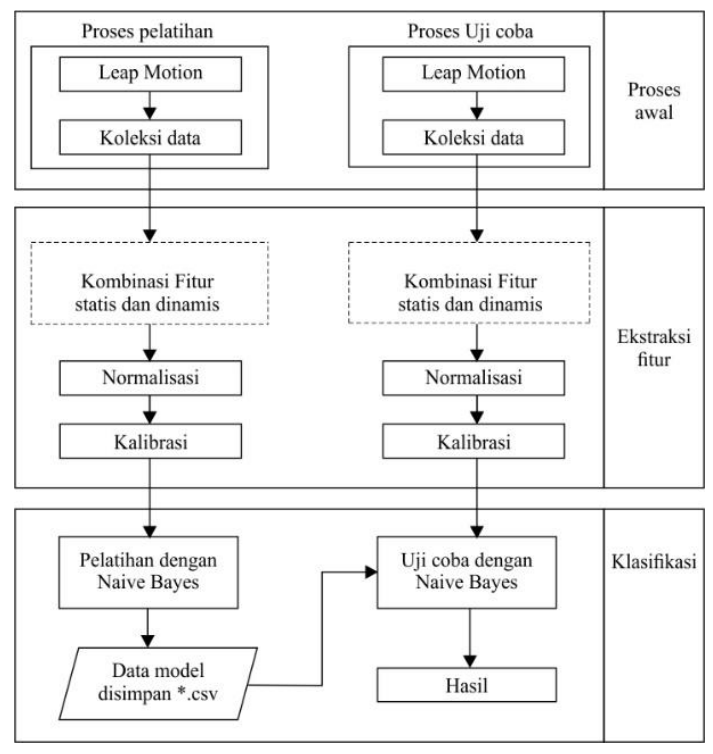

Gambar 3.2 Metode Sistem akurasi dan presisi interaksi pada benda virtual.

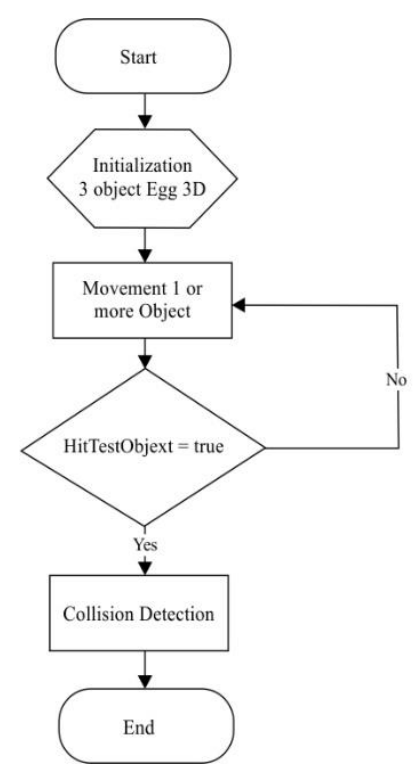

Gambar 3.3 Flowchart Game - Collision Detection.

Pada gambar 3.3 adalah flowchart untuk sistem arsitektur game simulasi menggenggam benda palstis menggunkana objek benda telur virtual dengan implementasi algoritma collision detection yang difungsikan agar ketika tangan menggenggam benda 3D tidak menembus dinding pembatas objek benda 3D atau benda virtual. Collision detection ini yang kemudian mampu mendeteksi tingkat presisi genggaman tangan ke objek benda Virtual.

\section{HASIL DAN PEMBAHASAN}

Hasil uji coba eksperimen dan analisa pengujian dilakukan secara real time dengan menggunakan telur virtual sebagai bahan interaksi terhadap benda maya untuk mencari tingkat akurasi dan presisi. Berikut data yang diperoleh pada saat interaksi tangan pada benda objek virtual.

Tabel 4.1 Hasil uji coba eksperimen dan analisa pengujian

\begin{tabular}{|c|c|c|c|c|c|c|}
\hline No. & Genggaman & $\begin{array}{c}\text { Nilai } \\
X, Y \\
\text { dan } \\
Z \\
\end{array}$ & Presisi & Akurasi & $\begin{array}{l}\text { Posisi } \\
\text { Jarak }\end{array}$ & Status \\
\hline 1. & $\begin{array}{c}\text { Tangan } \\
\text { kanan }\end{array}$ & $\begin{array}{c}\mathrm{X}= \\
1 \\
\mathrm{Y}= \\
1 \\
\mathrm{Z}=0\end{array}$ & 0.627 & 0.632 & $\begin{array}{c}0 \mathrm{~cm}- \\
5 \mathrm{~cm}\end{array}$ & False \\
\hline 2. & $\begin{array}{c}\text { Tangan } \\
\text { kanan }\end{array}$ & $\begin{array}{c}\mathrm{X}= \\
0 \\
\mathrm{Y}= \\
1 \\
\mathrm{Z}=1\end{array}$ & 0.616 & 0.719 & $\begin{array}{l}5 \mathrm{~cm}- \\
10 \mathrm{~cm}\end{array}$ & False \\
\hline 3. & $\begin{array}{l}\text { Tangan } \\
\text { kanan }\end{array}$ & $\begin{array}{c}\mathrm{X}= \\
1 \\
\mathrm{Y}= \\
1 \\
\mathrm{Z}=0\end{array}$ & 0.927 & 0.931 & $\begin{array}{c}10 \\
\mathrm{cm-} \\
15 \mathrm{~cm}\end{array}$ & True \\
\hline 4. & $\begin{array}{c}\text { Tangan } \\
\text { kanan }\end{array}$ & $\begin{array}{c}\mathrm{X}= \\
0 \\
\mathrm{Y}= \\
1 \\
\mathrm{Z}=0\end{array}$ & 0.934 & 0.946 & $\begin{array}{c}15 \\
\mathrm{~cm}- \\
20 \mathrm{~cm}\end{array}$ & True \\
\hline 5. & $\begin{array}{c}\text { Tangan } \\
\text { kanan }\end{array}$ & $\begin{array}{c}\mathrm{X}= \\
0 \\
\mathrm{Y}= \\
0 \\
\mathrm{Z}=1\end{array}$ & 0.922 & 0.907 & $\begin{array}{c}20 \\
\mathrm{~cm}- \\
25 \mathrm{~cm}\end{array}$ & True \\
\hline 6. & Tangan kiri & $\begin{array}{c}\mathrm{X}= \\
1 \\
\mathrm{Y}= \\
0 \\
\mathrm{Z}=0\end{array}$ & 0.620 & 0.625 & $\begin{array}{c}0 \mathrm{~cm}- \\
5 \mathrm{~cm}\end{array}$ & False \\
\hline 7. & Tangan kiri & $\begin{array}{c}\mathrm{X}= \\
1 \\
\mathrm{Y}= \\
1 \\
\mathrm{Z}=0\end{array}$ & 0.614 & 0.711 & $\begin{array}{l}5 \mathrm{~cm}- \\
10 \mathrm{~cm}\end{array}$ & False \\
\hline 8. & Tangan kiri & $\begin{array}{c}\mathrm{X}= \\
0 \\
\mathrm{Y}= \\
1 \\
\mathrm{Z}=1\end{array}$ & 0.933 & 0.926 & $\begin{array}{c}10 \\
\mathrm{~cm}- \\
15 \mathrm{~cm}\end{array}$ & True \\
\hline 9. & Tangan kiri & $\begin{array}{c}\mathrm{X}= \\
1 \\
\mathrm{Y}= \\
0 \\
\mathrm{Z}=1\end{array}$ & 0.931 & 0.938 & $\begin{array}{c}15 \\
\mathrm{~cm}- \\
20 \mathrm{~cm}\end{array}$ & True \\
\hline 10. & Tangan kiri & $\begin{array}{c}\mathrm{X}= \\
0 \\
\mathrm{Y}= \\
0 \\
\mathrm{Z}=1\end{array}$ & 0.922 & 0.907 & $\begin{array}{c}20 \\
\mathrm{~cm}- \\
25 \mathrm{~cm}\end{array}$ & True \\
\hline
\end{tabular}

Jika nilai margin prediksinya mendekati angka 1 maka hasil prediksi adalah "True" dan sebaliknya jika mendekati nilai 0 atau minus maka hasil prediksi "false".

Untuk mencari nilai probabilitas pada tangan kanan dan kiri mengggunakan rumus berikut:

$$
P(\text { probabilitas })=\frac{N}{\text { Jumlah }}
$$


CYCLOTRON

VOLUME 3 NOMOR 2, JULI 2020

Tabel 4.2 Probabilitas objek pada tangan kanan dan kiri

\begin{tabular}{|l|c|c|}
\hline Probabilitas & Tangan kanan & Tangan Kiri \\
\hline $\begin{array}{l}\text { Probabilitas } \\
\text { berhasil }\end{array}$ & $\frac{3}{5}=0,6$ & $\frac{3}{5}=0,6$ \\
\hline Probabilitas gagal & $\frac{2}{5}=0,4$ & $\frac{2}{5}=0,4$ \\
\hline
\end{tabular}

Tabel 4.3 Probabilitas objek pada faktor presisi

\begin{tabular}{|l|c|c|}
\hline Probabilitas & Tangan kanan & Tangan Kiri \\
\hline Probabilitas baik & $\frac{3}{5}=0,6$ & $\frac{3}{5}=0,6$ \\
\hline Probabilitas buruk & $\frac{2}{5}=0,4$ & $\frac{2}{5}=0,4$ \\
\hline
\end{tabular}

Tabel 4.4 Probabilitas objek pada faktor akurasi

\begin{tabular}{|l|c|c|}
\hline Probabilitas & Tangan kanan & Tangan Kiri \\
\hline Probabilitas baik & $\frac{3}{5}=0,6$ & $\frac{3}{5}=0,6$ \\
\hline Probabilitas buruk & $\frac{2}{5}=0,4$ & $\frac{2}{5}=0,4$ \\
\hline
\end{tabular}

Tabel 4.5 Probabilitas objek pada faktor jarak

\begin{tabular}{|l|c|c|}
\hline Probabilitas & Tangan kanan & Tangan Kiri \\
\hline Probabilitas baik & $\frac{3}{5}=0,6$ & $\frac{3}{5}=0,6$ \\
\hline Probabilitas buruk & $\frac{2}{5}=0,4$ & $\frac{2}{5}=0,4$ \\
\hline
\end{tabular}

Probabilitas pada tangan kanan

$$
\begin{gathered}
P \mid \text { Berhasil }=P(\text { tangan kanan }) * P(\text { Presisi }) * P(\text { Akurasi }) * P(\text { Jarak }) \\
P \mid \text { Berhasil }=0,6 * 0,6 * 0,6 * 0,6=0,1296 \\
P \mid \text { Gagal }=P(\text { tangan kanan }) * P(\text { Presisi }) * P(\text { Akurasi }) * P(\text { Jarak }) \\
P \mid \text { Berhasil }=0,4 * 0,4 * 0,4 * 0,4=0,0256
\end{gathered}
$$

Kesimpulan $\boldsymbol{P} \mid$ Berhasil $>P \mid$ Gagal

Probabilitas pada tangan kiri

$$
\begin{gathered}
P \mid \text { Berhasil }=P(\text { tangan kir }) * P(\text { Presisi }) * P(\text { Akurasi }) * P(\text { Jarak }) \\
P \mid \text { Berhasil }=0,6 * 0,6 * 0,6 * 0,6=0,1296 \mid \\
P \mid \text { Gagal }= \\
P(\text { tangan kiri }) * P(\text { Presisi }) * P(\text { Akurasi }) * P(\text { Jarak }) \\
P \mid \text { Berhasil }=0,4 * 0,4 * 0,4 * 0,4=0,0256
\end{gathered}
$$

\section{Kesimpulan $\boldsymbol{P} \mid$ Berhasil $>P \mid$ Gagal}

Dari pengujian yang dilakukan di atas dijelaskan penggunaan sensor Leap Motion berbentuk tiga dimensi pada setiap dimensinya memiliki sumbu untuk menentukan

\begin{tabular}{|c|c|c|c|c|c|c|}
\hline & & $\begin{array}{c}\mathrm{Y}= \\
1 \\
\mathrm{Z}=0\end{array}$ & & & & \\
\hline 2. & Tangan kiri & $\begin{array}{c}\mathrm{X}= \\
1 \\
\mathrm{Y}= \\
0 \\
\mathrm{Z}=1\end{array}$ & 0.931 & 0.938 & $\begin{array}{c}15 \\
\mathrm{~cm}- \\
20 \mathrm{~cm}\end{array}$ & $\begin{array}{c}\text { Baik } \\
\text { Sekali }\end{array}$ \\
\hline
\end{tabular}
nilai yaitu sumbu $\mathrm{X}, \mathrm{Y}$ dan $\mathrm{Z}$. Pada setiap sumbu dapat ditentukan berapa nilai yang di inginkan untuk mentracking tangan ketika melakukan simulasi menggenggam telur virtual.

Tabel 4.12 Hasil nilai terbaik uji eksperimen data interaksi menggenggam telur virtual.

\begin{tabular}{|c|c|c|c|c|c|c|}
\hline No. & Genggaman & $\begin{array}{c}\text { Nilai } \\
\mathbf{X}, \mathbf{Y} \\
\text { dan } \\
\mathbf{Z}\end{array}$ & Presisi & Akurasi & $\begin{array}{c}\text { Posisi } \\
\text { Jarak }\end{array}$ & Status \\
\hline 1. & $\begin{array}{c}\text { Tangan } \\
\text { kanan }\end{array}$ & $\begin{array}{c}\mathrm{X}= \\
0\end{array}$ & 0.934 & 0.946 & $\begin{array}{c}15 \\
\mathrm{~cm}- \\
20 \mathrm{~cm}\end{array}$ & $\begin{array}{c}\text { Baik } \\
\text { Sekali }\end{array}$ \\
\hline
\end{tabular}

Dari Tabel 4.5 hasil uji eksperimen dan analisa diambil data terbaik tangan kanan dan kiri hasil interaksi menggenggam benda atau object virtual dengan sensor leap motion perbandingan data dari Table 4.4 pada nomor 4 dan nomor 9 memiliki nilai akurasi dan presisi yang nilainya besar. Posisi jarak terbaik untuk menggenggam telur virtual berada pada jarak radius $15 \mathrm{~cm}-20 \mathrm{~cm}$. tingkat presisi: tangan kanan 0.934 dan tangan kiri 0.931 kemudian tingkat akurasi: tangan kanan 0.946 dan tangan kiri 0.938 .

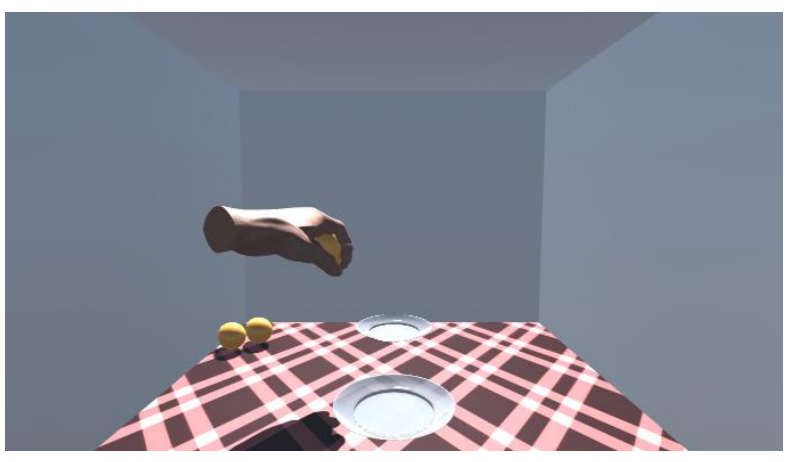

Gambar 4.1 Gambar interaksi tangan kiri menggenggam telur virtual.

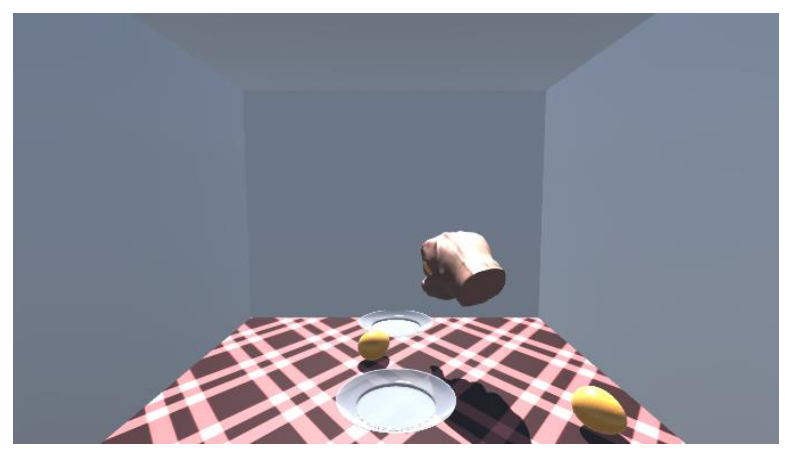

Gambar 4.2 Gambar interaksi tangan kanan menggenggam telur virtual.

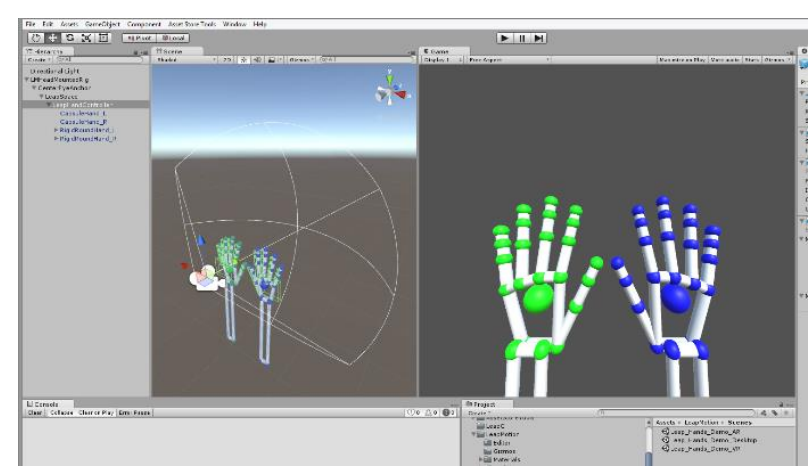

Gambar 4.3 Gambar ruas garis lengkung jarak dan juga batas area Leap Motion. 


\section{KESIMPULAN}

Dari hasil pengamatan dan eksperimen yang dapat diambil selama penulis melakukann penelitian menggunakan metode Naïve Bayes dan collision detection untuk mendapatkan hasil yang maksimal untuk kedepan sebagai upaya penelitian lanjutan adalah Data Tidak Baik presisi dan akurasi untuk interaksi menggenggam telur virtual di perolek jarak radius $0 \mathrm{~cm}-5 \mathrm{~cm}$. Data terbaik presisi dan akurasi untuk interaksi menggenggam telur virtual di perolek jarak radius $30 \mathrm{~cm}-35 \mathrm{~cm}$. Massa (bobot) benda didalam desain 3D juga berpengaruh pada interaksi benda virual (terlur virtual). Nilai data traning menggunakan naïve bayes yang margin prediksinya mendekati angka 1 maka hasil prediksi adalah "True" dan sebaliknya jika mendekati nilai 0 atau minus maka prediksi adalah "false".

Dengan mengkombinasikan fitur statis dan fitur dinamis yang di dapatkan dari perangkat sensor Leap Motion untuk interaksi akurasi dan presisi menggenggam telur virtual bahwa kombinasi metode naïve bayes dan collision detection dapat diaplikasikan untuk memperoleh nilai hasil penelitian dengan nilai tangan kanan 0.934 dan tangan kiri 0.931 kemudian tingkat akurasi tangan kanan 0.946 dan tangan kiri 0.938 .

\section{REFERENSI}

[1] Achmad, B., Firdausy, K, Teknik Pengolahan Citra Digital menggunakan Delphi, Ardi Publising, Yogyakarta, 2005.

[2] D. Bassily, "Intuitive and Adaptive Robotic Arm Manipulation using the Leap Motion Controller," Conference ISR ROBOTIK 2014, 2014.

[3] E. Tsironi, P. Barros, C. Weber, and S. Wermter, 2017. "An analiysis of convolution long short-term memory recurrent neural networks for gesture recognition. Neurocomputing, 268:76-86.

[4] F. Despinoy, N. Zemiti, G. Forestier, A. Sanchez, P. Jannin, dan P. Poignet, 2018. "Evaluation of Contactless Human Interface for Robotic Surgical Training", "International Jurnal of Computer Assisted Radiology and Surgery, vol. 13, no 1, pp, 13-24.

[5] Giulio Marin, "Hand Gesture Recognition with Leap Motion and Kinect Devices,” ICIP 2014, 2014.

[6] Guyton, Arthur C, Fisiologi Kedokteran, 148 - 168, Edisi ke 5, EGC, Jakarta, 1987.

[7] Hao Tian, Changbo Wang, Dinesh Manocha,Fellow, Xinyu Zhang, 2015. "Realtime Hand-Object Interaction using Learned Grasp Space for Virtual Environments", DOI 10.1109/TVCG.2018.2849381, IEEE.

[8] Hannah Slay, Matthew Phillips, Dr Rudi Vernik, and Dr Bruce Thomas, 2001. "Interaction Modes for Augmented Reality Visualization

[9] Haryono, 2000. "Langkah-Langkah Teknis Uji Kualitas Telur Konsumsi Ayam Ras". Balai Penelitian Ternak Bogor.

[10] Jin H, Chen Q, Chen Z, Hu Y, Zhang J, 2016 MultiLeapMotion sensor based demonstration for robotic refine tabletop object manipulation task. Transactions on Intelligence Technology 1(1):104-113

[11] K. Y. Lian, C.-C. Chiu, Y.-J Hong, and W.-T. Sung, 2017. "Wereable armband for real time hand gesture recognition. In System, Man and Cybernetics(SMC), 2017. IEEE International Conference on, page 2992-2995. IEEE.

[12] L. Motion, 2017. "Leap Motion SDK and Plugin Documentation". [Online]. Available: https://developer.leapmotion.com/.

[13] M. Mohandes, 2014. "Arabic Sign Language Recognition using the Leap Motion Controller," King Fahd University of Petroleum \& Minerals Dhahran, 31261.
[14] M. Deriche, M. Mohandes, S. Aliyu, 2015. "Prototype Arabic Sign Language Recognition using Multi-Sensor Data Fusion of Two Leap Motion

Controllers". pp.1-6.

[15] Moglia A, Ferrari V, Morelli L, Ferrari M, Mosca F, Cuschieri A 2016. A Systematic Review of Virtual Reality Simulators for Robot-assisted Surgery. European Urology 69(6): $1065\{1080$

[16] Nugraha, R.M., 2011. Penggunaan Struktur Data Quad-Tree dalam Algoritma Collision Detection pa da Vertical Shooter Game, Makalah IF3051 Strategi Algoritma, Program Studi Teknik Informatika, Sekolah Teknik Elektro dan Informatika, Bandung.

[17] R. Meziane, M. J.-D. Otis, and H. Ezzaidi, 2017. "human-robot collaboration while sharing production activities in dynamic environment: Spader system, "Robotics and Computer Integrated Manufacturing, vol. 48, pp. 243-253.

[18] Sukamti, Endang R. Diktat Perkembangan Motorik. Yogyakarta: FIK UNY, 2007.

[19] Sumantri, "Model Pengembangan keterampilan Motorik Anak Usia Dini". Jakarta: Depdikbut, 2005. 